\title{
Conservadorismo e independência no Banco Central do Brasil
}

\author{
Roberto Meurer
}

RESUMO - O Banco Central do Brasil é sistematicamente criticado por suas decisões sobre a taxa básica de juros (SELIC), acusado de ser excessivamente preocupado ou muito leniente com a inflação. Caso o Banco Central estivesse tendo um viés sistemático em suas decisões, a taxa de inflação deveria estar muito mais alta ou muito mais baixa do que a observada, a despeito de as taxas serem muito mais vezes elevadas do que baixas em relação ao centro da meta. O Banco Central não pode estar simplesmente sendo manipulado pelo mercado financeiro, no qual há interesses distintos em jogo.

Palavras-chave: Política monetária. Banco Central do Brasil. Mercado financeiro.

Ao se efetuar o acompanhamento do noticiário sobre decisões do COPOM após mais de uma década de operação do sistema de metas de inflação, a aparência é de que o Banco Central do Brasil está sempre errado ao tomar sua decisão sobre a meta para a taxa SELIC, a taxa básica de juros da economia brasileira. Por um lado há a reclamação sistemática de setores empresarias e de sindicatos de trabalhadores de que a taxa SELIC é elevada demais, independentemente da decisão tomada ou do nível em que a taxa se encontra. Por outro, parece que o Banco Central tem de mostrar a cada reunião que é independente do Poder Executivo e que suas decisões não são tomadas pelo Ministério da Fazenda. Este artigo discute a possibilidade de o Banco Central errar sistematicamente com juros muito elevados ou ser manipulado pelo mercado financeiro no contexto do sistema de metas para a inflação.

As decisões sobre política monetária têm potencial para gerar polêmica pelo simples fato de não serem neutras do ponto de vista distributivo. Mesmo que se considere que no longo prazo a taxa real de juros tenda à taxa neutra, as decisões da autoridade monetária no curto prazo têm efeitos sobre fluxos de renda e estoques de ativos e passivos da sociedade. Isto ocorre tanto por efeitos diretos sobre a renda, a partir de títulos públicos e privados cujo rendimento é atrelado à taxa SELIC e seu correspondente privado, a taxa do CDI, quanto através dos efeitos gerados a partir da estrutura a termo da taxa de juros.

A influência da taxa de juros de curtíssimo prazo sobre a renda é um dos fatores de amortecimento do poder da política monetária. Uma taxa de juros mais elevada tem efeito expansionista sobre o produto, porque a remuneração de parte dos ativos financeiros aumenta, o que gera elevação da renda disponível e, por consequência, maior demanda. Este é um efeito * Doutor em Engenharia de Produção pela Universidade Federal de Santa Catarina. É professor do Departamento de Economia da Universidade Federal de Santa Catarina. Endereço eletrônico: robertomeurer@yahoo.com. 
com o sinal contrário ao do tradicional canal da riqueza, em que a elevação da taxa de juros reduz o valor presente dos ativos financeiros, empobrecendo os detentores dos títulos e, deste modo, inibindo a demanda. Isto significa que a indexação dos ativos financeiros amortece o efeito da política monetária, ao mesmo tempo em que a decisão sobre os juros tem efeitos imediatos sobre a renda e, inversamente, sobre os custos para o governo e outros emissores de passivos indexados às taxas de juros de curtíssimo prazo. Para se ter uma ideia dos volumes envolvidos, a participação das Letras Financeiras do Tesouro (LFT), cujo rendimento é a taxa SELIC, era de 33,3\% da dívida do Governo Federal em títulos, o equivalente a 553 bilhões de reais, em julho de 2011. Isto quer dizer que uma alteração de um ponto percentual na taxa de juros representa uma alteração de 5,5 bilhões de reais em um ano no rendimento e custo dessa dívida. No mesmo período o estoque de CDBs (Certificado de Depósito Bancário), cujo rendimento é atrelado à taxa do CDI registrados na CETIP, era de 610 bilhões de reais, o que representa aproximadamente $75 \%$ do estoque de títulos emitidos pelo sistema financeiro. Isto mostra que a taxa básica de juros da economia afeta todo o sistema financeiro; o seu efeito não é restrito às contas do governo.

Os efeitos da taxa de juros sobre o estoque de riqueza através dos deslocamentos da curva de rendimento também não são desprezíveis. Alterações de juros não previstas afetam os juros de prazos mais longos, pelo efeito nas expectativas para as taxas mais longas. Isto afeta tanto os valores presentes de ativos e passivos prefixados com prazos mais longos, quanto operações com derivativos que envolvem taxas de juros de diferentes prazos e, portanto, tem efeitos diretos de transferência de riqueza.

Esta discussão mostra que é inevitável que sejam contrariados interesses na tomada de decisão por parte do Banco Central, a não ser que as expectativas sobre os juros futuros sejam iguais em toda a sociedade e, portanto, o mercado financeiro esteja trabalhando com preços que já incorporem totalmente estas expectativas. A uniformidade de expectativas, ou seja, a inexistência de comprados e vendidos (touros e ursos) no mercado é difícil de ocorrer, dada a vastidão de variáveis que as influenciam e a diversidade de interpretação do estado corrente e futuro da economia.

A crítica de que o Banco Central cede a pressões do Governo Federal ao não elevar suficientemente a taxa de juros equivale a dizer que o Banco Central busca manter o nível de produto acima do produto potencial. O sistema de metas para a inflação atribui ao Banco Central, explicitamente, o papel de atingir a meta para a inflação. No caso brasileiro, esta meta é considerada atingida também se a taxa estiver dentro de uma banda de tolerância, atualmente de $2 \%$. O fato de ter de cumprir a meta para a inflação não significa que o Banco Central não 
olhe para o produto. A crítica de que o Banco Central é leniente com a inflação, buscando maior nível de produto, significa que o Banco Central quer explorar o trade off entre produto e inflação caracterizado pela curva de Phillips. Na literatura de inconsistência temporal da política monetária isto equivaleria a buscar permanentemente obter um nível de produto superior ao potencial. O resultado seria uma trajetória de inflação crescente. Os bancos centrais não são ingênuos a ponto de adotar uma política monetária como essa, pelos óbvios custos que a inflação crescente geraria (BLINDER, 1999).

O fato de o Banco Central não acreditar na possibilidade de explorar o trade off entre inflação e produto por tempo indeterminado, como é reconhecido sistematicamente nas atas do COPOM, não exclui outras discussões relevantes para a condução da política monetária, como a decisão sobre o nível da meta para a taxa de inflação, que poderia estar muito elevado, e a perda de oportunidades de reduzir o nível da taxa de inflação na economia brasileira. A trajetória das taxas de inflação no período do regime de metas, a partir de 1999, mostra que a meta foi extrapolada em pelo menos três anos, esteve acima do centro da meta sem extrapolá-la em cinco anos e em somente quatro esteve abaixo do centro da meta. Os desvios dentro da banda de tolerância para a meta são muito maiores para cima do que abaixo do centro da meta. Entretanto, caso o Banco Central adotasse uma política monetária que visasse a manutenção do nível de produto acima do potencial em todos os anos, não seria possível manter a inflação dentro do intervalo de tolerância para uma mesma taxa por seis anos, como ocorreu de 2005 a 2010.

Caso o Banco Central fosse excessivamente conservador em relação à inflação, mantendo taxas de juros desnecessariamente elevadas durante todo o tempo, a consequência apareceria tanto na inflação quanto no produto. Uma taxa de juros real sistematicamente acima da taxa neutra para a inflação significaria que o produto estaria abaixo do potencial durante todo o tempo também. A operação da curva de Phillips, mesmo no curto prazo, faria com que o hiato de produto negativo levasse à diminuição constante das taxas de inflação, o que, entretanto, não é observado. Isto pode ser ilustrado pelas baixas e decrescentes taxas de desemprego observadas na economia brasileira em 2010 e 2011.

Uma questão próxima à discutida acima é a que envolve a possibilidade de o Banco Central, com o objetivo de coordenar as expectativas em torno da política monetária, ser manipulado por estas expectativas. Isto poderia se manifestar no fato de o Banco seguir sistematicamente os desejos do mercado. O mecanismo para isso poderia ser o levantamento Focus, feito pelo próprio Banco Central junto às instituições financeiras e mais alguns agentes do mercado. O Gráfico 1 mostra as previsões do boletim Focus para a decisão em relação à meta da taxa SELIC no fim do mês em que ocorre reunião do COPOM, divulgadas na segunda feira anterior 
à reunião. Isto significa, na prática, que esta previsão é sobre a decisão da reunião do COPOM, porque a taxa somente seria diferente no fim do mês se após a reunião prevista ocorresse mais uma extraordinária que alterasse a taxa. O Gráfico 1 mostra uma clara convergência entre as previsões do boletim Focus e as decisões do COPOM a partir da reunião de 21/05/2003. Antes disso, em geral o COPOM teve decisões mais contracionistas do que o esperado pelo levantamento de expectativas.

GRÁFICO 1 - EXPECTATIVA DE MERCADO BOLETIM FOCUS E DECISÃO DO COPOM SOBRE A META PARA A TAXA SELIC
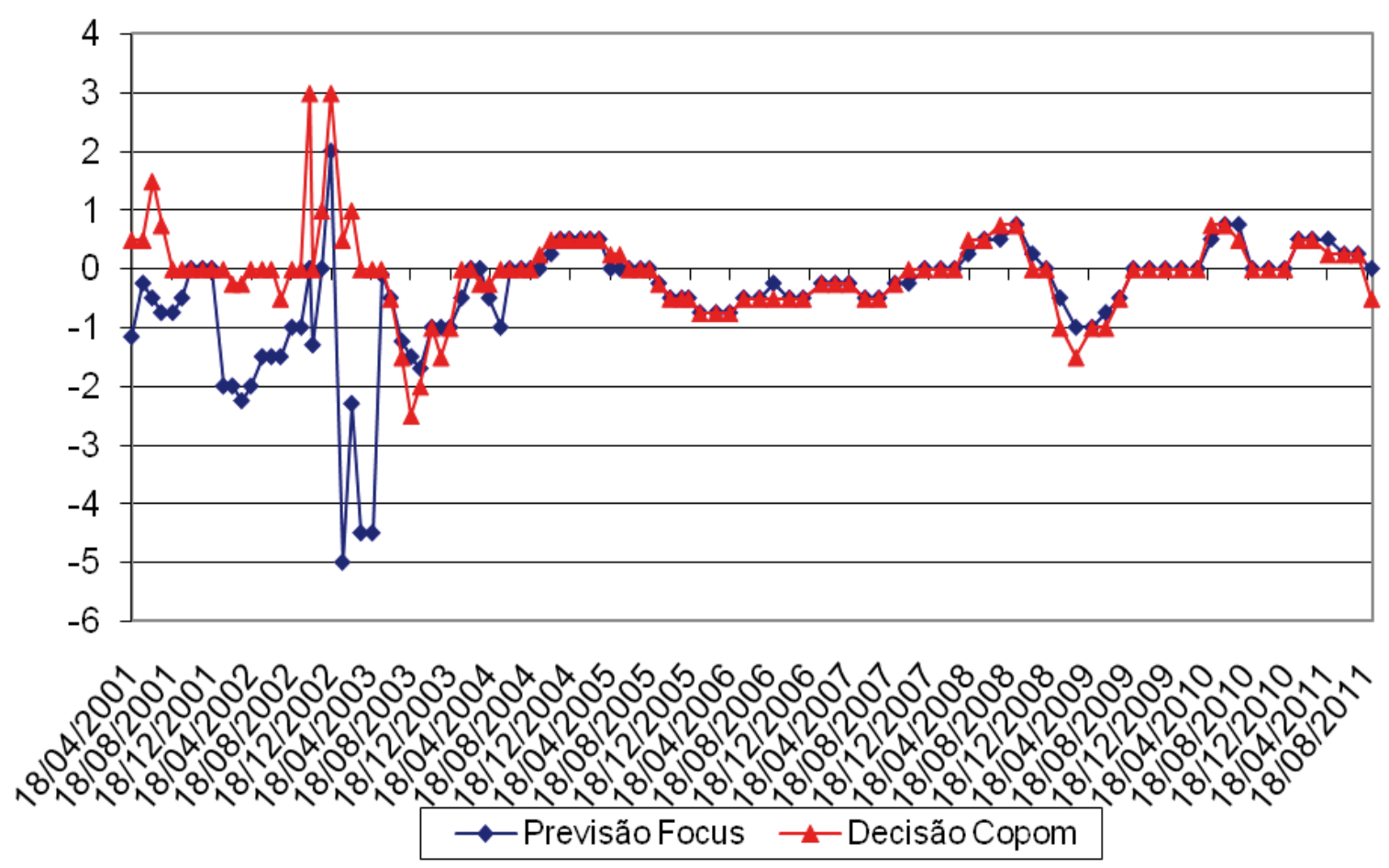

FONTE: Banco Central do Brasil.

A partir de meados de 2003 o boletim Focus (ou o Banco Central) "acerta" mais as decisões. As explicações para esta maior convergência, sem considerar teorias conspiratórias, podem estar relacionadas com o próprio amadurecimento dos rituais envolvidos no sistema de metas de inflação, que incluem o levantamento de expectativas quanto a mudança nos fundamentos macroeconômicos da economia brasileira.

Após o choque causado pela depreciação da moeda com a impossibilidade de manutenção da taxa de câmbio semifixo no início de 1999, a economia brasileira continuou sofrendo influências que não eram decorrentes somente da política monetária adotada pelo Banco Central. Isto incluiu a crise argentina, ao longo de 2001, e uma minicrise cambial no Brasil em 2002, decorrente do medo da chegada de Lula à Presidência da República. A fuga de capitais e a depreciação da moeda brasileira como consequência levaram à disparada da inflação com o 
repasse cambial. O descolamento entre as decisões do Banco Central e as expectativas do Focus eram anteriores à chegada de Lula ao poder. Quando Lula tranquilizou os mercados, mantendo a independência operacional do Banco Central, isto ficou evidenciado pela adoção de uma política monetária mais contracionista que o esperado pelo boletim Focus. O aprofundamento do superávit fiscal e a continuidade da melhoria das contas externas, decorrente da depreciação cambial, que levou à geração de superávit em transações correntes, significaram uma maior liberdade na utilização da política monetária para influenciar inflação e produto. Em outras palavras, a melhoria dos fundamentos macroeconômicos permitiu o deslocamento do foco da política monetária da necessidade de atração de capitais externos para o fechamento do balanço de pagamentos para variáveis domésticas.

As menores oscilações das taxas de juros internas com a melhoria dos fundamentos macroeconômicos refletem o aumento do poder da política monetária, decorrente de maior participação dos títulos prefixados na dívida pública, o que também decorre de maior previsibilidade da taxa de inflação, que influencia também o alongamento de prazo dos contratos financeiros.

A maior previsibilidade da política monetária incorpora também a suavização dos juros. Como os juros não são mais elevados ou reduzidos em reação apenas ao fluxo de financiamento externo, o horizonte de planejamento da política monetária, dada a defasagem da sua operação, aumenta. Para evitar overshooting da política monetária, decorrente das incertezas de parâmetros dos modelos utilizados para verificar os efeitos da política e os erros inerentes à previsão das variáveis exógenas, os movimentos na taxa de juros não são executados na magnitude que leve ao atingimento imediato das metas de inflação e produto. Em outras palavras, como é preferível fazer a economia chegar suavemente à meta de inflação e ao produto potencial ao invés de correr riscos de superaquecer ou desaquecer excessivamente a economia, o que exigiria movimentos cada vez maiores das taxas de juros com sinais trocados, os movimentos das taxas de juros são menos intensos. Este comportamento, que facilita a adaptação dos mercados financeiros a mudanças nas taxas sem oscilações muito grandes no valor presente de ativos e passivos, é incorporado às previsões, e em geral seguido pelo Banco Central.

A possibilidade de manipulação do Banco Central pelo mercado financeiro teria de ser qualificada, porque não há ganho unilateral dos bancos com juros elevados. Por um lado, os bancos têm carteira própria de títulos que é influenciada pelo rendimento gerado pelas taxas de curtíssimo prazo. Por outro, em seu ativo os bancos têm contratos prefixados de prazos mais longos que seus passivos que, por consequência, têm seu valor presente mais sensível a mudanças nas taxas de juros que o seu passivo. Isto decorre do papel do sistema financeiro de 
transformar prazos curtos no passivo em prazos mais longos no ativo, o qual ainda não é realizado na medida ideal no sistema financeiro brasileiro. A própria queda da taxa real de juros da economia brasileira ao longo dos últimos anos (Gráfico 2) faz com que os bancos sejam induzidos a procurar alternativas de aplicação de recursos mais rentáveis que os títulos do Governo ou ativos atrelados a taxas de juros de curtíssimo prazo, o que explica, pelo menos em parte, a elevação do volume de crédito na economia brasileira ao longo da última década.

GRÁFICO 2 - TAXA REAL DE JUROS - SELIC (\% A.A.) - DEFLATOR IPCA

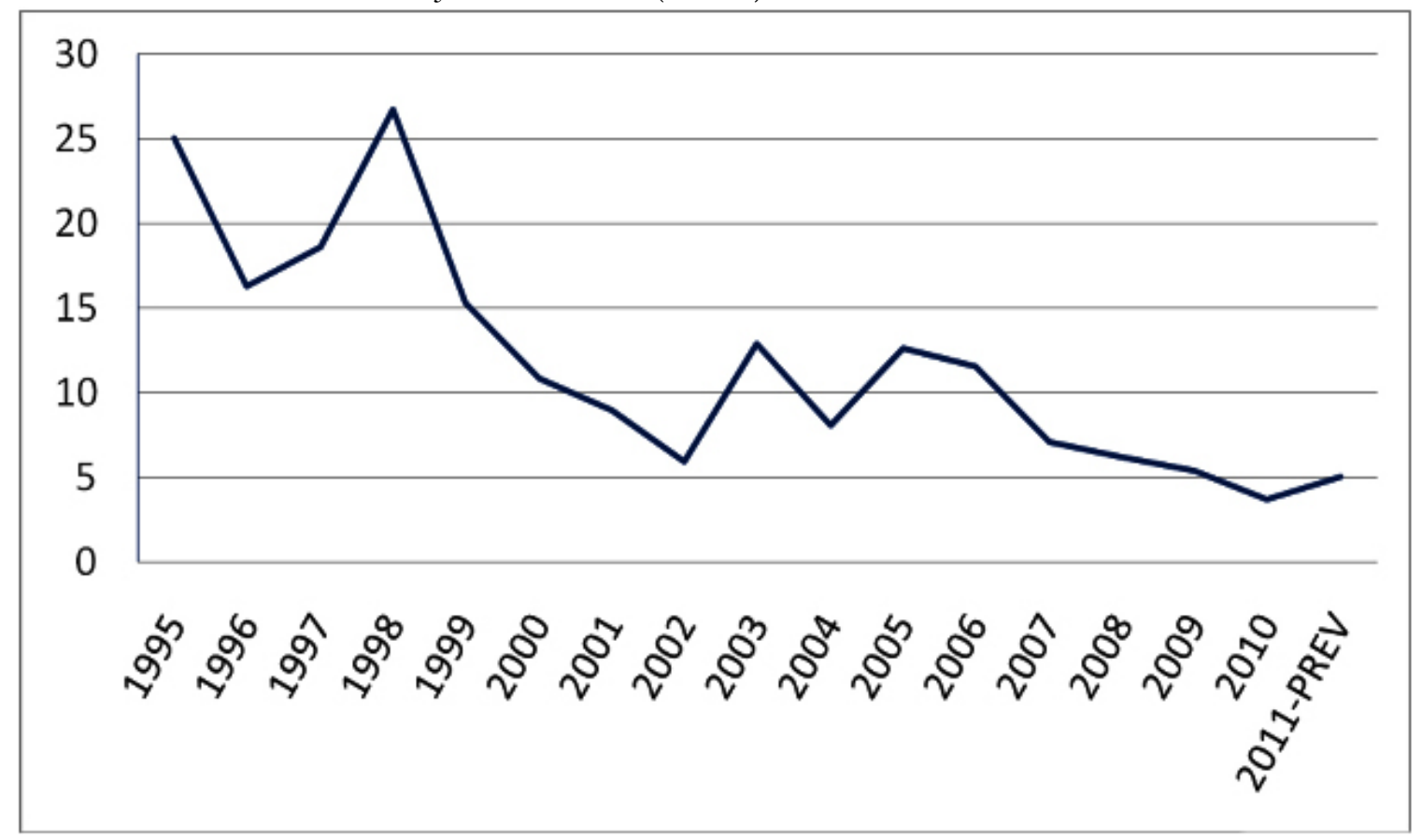

FONTE: Calculado a partir de dados do Banco Central do Brasil.

Um aspecto que pode estar influenciando a política monetária, permitindo a redução das taxas de juros e, ao mesmo tempo, influenciando este processo, é o câmbio. A apreciação da moeda brasileira a partir de 2003, revertendo o efeito inflacionário gerado no período imediatamente anterior à eleição presidencial de 2002, tem papel importante no controle da inflação. O grau de repasse cambial ocorrido durante este processo e a sensibilidade da inflação a uma eventual depreciação do real podem influenciar a política monetária futura. Por um lado, a apreciação da moeda brasileira pode refletir o diferencial de juros, mas também pode refletir um otimismo com o crescimento potencial da economia brasileira. Isto fica evidenciado pelo menor crescimento recente do preço dos produtos comercializáveis em relação ao preço dos produtos não comercializáveis, especialmente os serviços. Por outro lado, o próprio mercado financeiro atacaria uma taxa de câmbio que sistematicamente se afastasse do equilíbrio fundamental, que obviamente não é simples de ser determinado por envolver tanto transações correntes quanto 
financeiras, fortemente dependentes de expectativas e objeto de decisões especulativas.

A redução da taxa real de juros, para o que é importante a redução da dívida pública, reflete o aumento da potência da política monetária. Caso o mercado financeiro estivesse manipulando o Banco Central, esta redução dos juros seria mais difícil de ocorrer. O papel das variáveis macroeconômicas na determinação da política monetária continua fundamental, o que torna complicadas as decisões de política monetária, dada a instabilidade inerente a essas variáveis. O fato de a inflação não ter explodido e o produto não estar se reduzindo na economia indicam que a condução da política monetária no Brasil continua olhando para inflação, como é óbvio no regime de metas, e para produto, como é natural para tomadores de decisão razoáveis.

\section{REFERÊNCIAS}

BLINDER, A. S. Bancos centrais: teoria e prática. São Paulo: 34, 1999. 
